
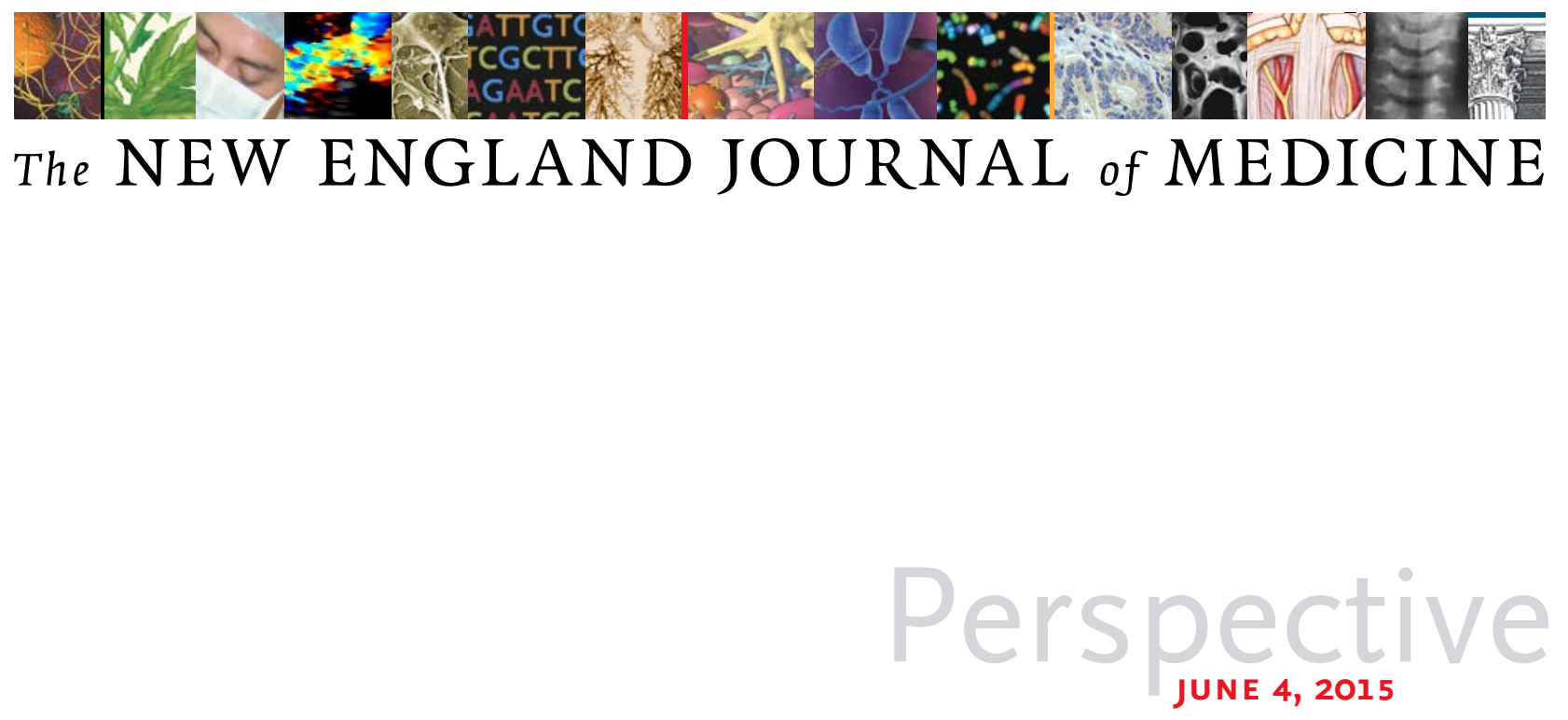

\title{
INTERNATIONAL HEALTH CARE SYSTEMS \\ Brazil's Family Health Strategy — Delivering Community-Based Primary Care in a Universal Health System
}

James Macinko, Ph.D., and Matthew J. Harris, M.B., B.S., D.Phil.

\section{Drazil has made rapid progress toward universal B coverage of its population through its national health system, the Sistema Unico de Saúde (SUS). Since its emergence from dictatorship in 1985, Brazil —}

which has the world's fifth-largest population and seventh-largest economy - has invested substantially in expanding access to health care for all citizens, a goal that is implicit in the Brazilian constitution and the principles guiding the national health system. ${ }^{1}$ The SUS comprises public and private health care institutions and providers, financed primarily through taxes with contributions from federal, state, and municipal budgets. Health care management is decentralized, and municipalities are responsible for most primary care services as well as some hospitals and other facilities. All publicly financed health services and most common medications are universally accessible and free of charge at the point of service for all citizens - even the $26 \%$ of the population enrolled in private health plans (see table). ${ }^{1}$

An important innovation in the system has been the development, adaptation, and rapid scaling up of a community-based approach to providing primary health care. After originating in the northeastern state of Ceará in the 1990s as a maternal and child health program relying on community health agents (lay members of the community who are paid members of the health care team), the Family Health Program (now called the Family Health Strategy, or FHS) has evolved into a robust approach to providing primary care for defined pop- ulations by deploying interdisciplinary health care teams. The nucleus of each FHS team includes a physician, a nurse, a nurse assistant, and four to six full-time community health agents. Family health teams are organized geographically, covering populations of up to 1000 households each, with no overlap or gap between catchment areas. Each FHS team member has defined roles and responsibilities, and national guidelines help structure FHS responses to most health problems. The pace of FHS scale-up has been remarkable: from about 2000 teams including 60,000 community health agents providing services to 7 million people (4\% of the Brazilian population) in 1998 to 39,000 teams incorporating more than 265,000 community health agents, plus 30,000 oral health teams, together serving 120 million people (62\% of the population) in 2014. ${ }^{2}$ 
Perhaps the most important FHS component is the extensive and effective use of community health agents. Each agent is assigned to approximately 150 households in a geographically delineated micro-area within the catchment area - usually the same micro-area where the agent lives. Agents visit each household within their micro-area at least once per month, irrespective of need or demand, and collect individual- and household-level data. During each visit, they draw, as required, on a set of healthpromotion activities and basic clinical care that span the life course. They may ask household members why they missed an appointment (and help schedule a new one), check whether prescriptions have been filled and whether patients have been taking their medications regularly, ask about changes to household composi- tion, and identify potential warning signs of violence, neglect, truancy, or drug use, among other problems. They also actively look for risk factors such as smoking and symptoms of common chronic disease such as hypertension and diabetes. Community health agents thus help bridge the divide between primary care and public health efforts.

Designed to perform several important primary care functions, the FHS reflects many best practices. Access and first-contact care are facilitated by locating health care teams near people's homes. Lists of all residents in each geographic area permit delivery of longitudinal care, and each team is responsible for everyone in its catchment area. Comprehensive care is provided by interdisciplinary teams whose scope of practice has gradually increased. Such care is proactive, since the com- munity health agents seek out problems before patients arrive at the health post. Teams also deliver public health interventions, such as contact tracing and immunization campaigns.

Health care teams have expanded over time and increasingly include professionals such as dentists and dental technicians. Further support has been provided through the development of multidisciplinary primary care support teams known as Núcleos de Apoio à Saúde da Família that may include nutritionists, psychologists, social workers, psychiatrists, community pharmacists, physical education specialists, speech and hearing therapists, occupational therapists, gynecologist-obstetricians, geriatricians, general internists, public health specialists, and others.

Community and family orientations are achieved through the

Selected Characteristics of the Health Care System and Health Outcomes in Brazil.*

\section{Variable}

Health expenditures

Per capita (U.S. \$)

Percentage of GDP

Out-of-pocket (\% of private health expenditures) $\dagger$

Public sources (\% of total)

Health care coverage

Population covered in 2013

Source of funding

Estimated average annual physician income (U.S. \$) in $2013 \%$

Salaried general practitioner

Self-employed general practitioner

Salaried specialist (general surgeon)

Self-employed specialist (general surgeon)

Generalist-specialist balance (\%)

Generalists

Specialists

Access

No. of hospital beds per 10,000 population

No. of physicians per 1000 population in 2013

Total government health expenditures spent on mental health care in 2011 (\%)
Value

1056

9.3

57.8

46.4

$100 \%$ public system, $26 \%$ private insurance

Primarily taxes for the public system; mix of patient and employer payments for private insurance 
Table (Continued.)

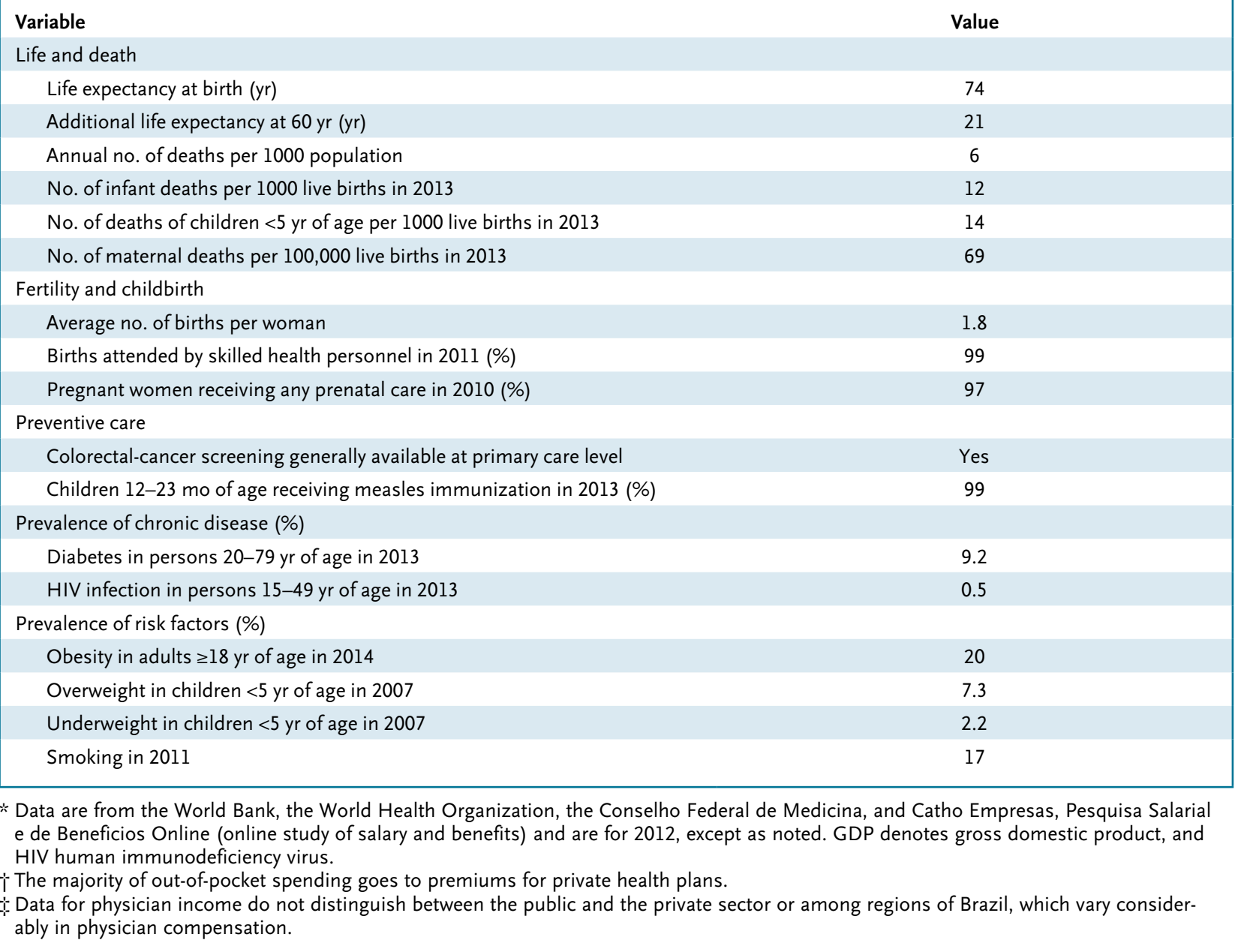

community health agents' home visits and through work with schools and community-based organizations. The FHS teams link health care users with social programs such as conditional cash transfer programs (in which people receive welfare payments if they keep their children in school and up to date with immunizations). The teams may also establish links to water and sanitation services, law enforcement, and schools. Coordination of care received elsewhere is ideally performed by the family health team, although this goal is perhaps the most difficult to achieve, given the national health sys- tem's limited availability of specialist and diagnostic services and uneven information-technology infrastructure.

Evidence suggests that the FHS provides better access and quality and results in greater user satisfaction than do traditional health posts and centers or even some private-sector health care facilities. ${ }^{3}$ Numerous studies have shown that FHS expansion has resulted in improvements in children's health, including large and sustained reductions in infant mortality, ${ }^{1}$ and in particular, postneonatal mortality due to diarrhea and respiratory infections. ${ }^{4}$ Among adults, FHS expansion has been associated with reduced mortality from cardiovascular and cerebrovascular causes, large reductions in hospitalization rates for ambulatory-care-sensitive conditions, and reduced rates of complications from some chronic conditions such as diabetes. ${ }^{5}$

Over the past decade, expansion of the family health program from its initial focus on poorer-than-average municipalities and regions has played an important role in reducing inequities in access to and utilization of care. ${ }^{1}$ There is also evidence that the FHS has improved detection of cases of neglected tropical diseases, reduced disparities 


\section{PREGNANCY AND CHILDBIRTH}

\section{A healthy 23-year-old woman is pregnant for the first time.}

When Ms. Silva suspects that she's pregnant, she first tells her trusted community health agent and neighbor, Ms. Oliveira. Ms. Oliveira makes an appointment for Ms. Silva at the Family Health Strategy (FHS) health post, where the nurse assistant checks her blood pressure and weight. Ms. Silva then attends a small-group session on pregnancy, labor, and breast-feeding, in which participants who have already had children also share their experiences. She may also attend a meditation class for pregnant women or participate in other programs available at some health posts.

Since Ms. Silva's pregnancy is normal, she receives prenatal care from the nurse, but if complications arise she will be referred to the physician on the family health team. She is given a card with her patient record, and the nurse fills in a copy for the health team's records. The nurse gives Ms. Silva information about pregnancy, syphilis, and human immunodeficiency virus, and provides any standard preventive care she needs, such as immunizations. Since her health post has a dentist, Ms. Silva takes the opportunity to have her teeth checked. She's then sent to the municipal health center to undergo blood and urine tests.

If Ms. Silva misses a prenatal care appointment, Ms. Oliveira checks in on her at home and helps her reschedule her visit. Any medications she requires are available free of charge at the health post, since Ms. Silva is registered with the FHS. She must pay only for travel to the municipal health center for tests and to the local maternity unit when she goes into labor. She will most likely have a normal vaginal delivery, although $\mathrm{C}$-sections are common $(>50 \%)$ among middle-class women with private health plans.

After delivery, postnatal care, including brief pediatric checks, will be in the maternity unit, but Ms. Silva will receive a home visit from Ms. Oliveira and the family health team nurse the day she returns home. Subsequent home visits will be scheduled depending on need. Ms. Oliveira and the nurse will monitor the baby's growth and development fortnightly at first, then monthly for the first 2 years.

in oral health, and even enhanced reporting of vital statistics.

Despite its many accomplishments, the Brazilian health system faces serious financial and organizational challenges. Although total health spending in Brazil is similar to the average of about $9 \%$ of gross domestic product (GDP) found among the countries of the Organization for Economic Cooperation and Development (OECD), less than half this amount comes from public sources - a proportion that places Brazil far below the OECD average for government share of health expenditures.

On the human resources front, rapid expansion of the FHS has led to a physician shortage that Brazil has responded to with the controversial Mais Médicos (More Doctors) program, importing nearly 15,000 physicians from Cuba and other countries. Since responsibility for managing the FHS lies with the municipalities, there are also large variations in the capacity and quality of the family health teams, including varied availability of basic equipment, varied staffing patterns and availability of different types of health professionals, and varied management and other institutional supports for the teams.

Like many health systems, the SUS struggles to meet the changing needs of a rapidly aging pop- ulation and to fulfill its constitutional mandate to achieve equitable access to services for all citizens. So far, the FHS program has focused on the poorer segments of many municipalities, and though that approach has improved health equity, it is challenging to reach middle-class Brazilians, who may prefer to seek services in the private sector.

At least partially in response to public protests regarding the need for greater public investment in health care, the Brazilian government has launched one of the world's largest pay-for-performance schemes within the FHS to accelerate investment in the public system. These new resources are contingent on measured improvements in the management of health services, technical quality of care, and user satisfaction.

Finally, technology use has been severely delayed in the SUS. New developments include proposals for the development of national electronic health records and enhanced access to diagnostic tools in primary care.

Still, the world can learn some lessons from the Brazilian experience. First, community-based primary care can work if done properly. It requires a solid blueprint, pilot testing and evidence generation, a long-term vision, and sustained financial and political commitments. The FHS appears to be extremely cost-effective: Brazil currently spends about $\$ 50$ annually per person on the program. ${ }^{4}$ But scaling up such an enterprise has required continuous adaptation and investment, especially in light of geographic differences in population health needs, differential municipal capacity and health care resources, and evolving medical practice a challenge likely to apply in other countries as well. Finally, build- 


\title{
MYOCARDIAL INFARCTION
}

A 55-year-old man with no serious health conditions has a moderately severe myocardial infarction.

When Mr. Santos feels chest pain, he goes right over to the local Family Health Strategy (FHS) health post and is seen by a physician immediately. He is placed in the observation room, where he is given oxygen and a painkiller. The health post lacks electrocardiography (ECG) equipment, so the physician calls an ambulance, which, since the health post is $5 \mathrm{~km}$ from town, takes 20 minutes to arrive.

At the hospital, Mr. Santos is taken first to the secondary care clinic, where his myocardial infarction is confirmed on ECG. If appropriate, he is then given thrombolytic agents. However, because of the severity of the infarction, he is transferred to the university hospital intensive care unit to undergo angioplasty. He remains in the hospital for 6 days.

The day he returns home, Mr. Santos is visited by his community health agent, who lives nearby and who helps him understand the purposes of his new medications and work out an administration schedule. She also talks to him about recommended dietary changes and offers lifestyle advice on such topics as smoking cessation, weight loss, and physical activity. Then she arranges for the physician who first saw Mr. Santos at the FHS post to visit him at home. Unfortunately, the patient was not given a discharge summary, so the physician has no way of knowing what treatment he received in the hospital, except for the aspects that Mr. Santos was told about and understood. Planned technology implementation should eventually allow information transfer from the hospital to the health posts.

The physician arranges for Mr. Santos to receive home visits from a Núcleos de Apoio à Saúde da Família - a team that includes a physiotherapist and a psychologist, among others. All these services are paid for by Mr. Santos's municipality and the Brazilian government.

ing a robust primary care system is more than a bureaucratic exercise; in Brazil, it has required long-term social movements and professional commitments.

The future of Brazil's FHS, its sustained expansion to the remaining urban centers and the middle classes, and its effective integration into secondary and tertiary care will require continued engagement by health care providers and the public and continued financial, technical, and intellectual investments - all of which ultimately depend on sustained political support.

Disclosure forms provided by the authors are available with the full text of this article at NEJM.org.

From the Departments of Health Policy and Management and Community Health Sciences, UCLA Fielding School of Public Health, Los Angeles (J.M.); the Harkness Fellowship Program in Health Care Policy and Practice, Commonwealth Fund, and New York University, New York (M.J.H.); and the School of Public Health, Imperial College London, London (M.J.H.).

1. Paim J, Travassos C, Almeida C, Bahia L, Macinko J. The Brazilian health system: history, advances, and challenges. Lancet 2011; 377:1778-97.

2. Histórico de Cobertura da Saúde da Familia. Brasilia, Brazil: Departamento de Atenção Básica, 2015 (http://dab.saude.gov.br/ portaldab/historico_cobertura_sf.php).

3. Macinko J, Lima Costa MF. Access to, use of and satisfaction with health services among adults enrolled in Brazil's Family Health Strategy: evidence from the 2008 National Household Survey. Trop Med Int Health 2012;17:36-42.

4. Rocha R, Soares RR. Evaluating the impact of community-based health interventions: evidence from Brazil's Family Health Program. Health Econ 2010;19:Suppl:126-58. 5. Rasella D, Harhay MO, Pamponet ML, Aquino R, Barreto ML. Impact of primary health care on mortality from heart and cerebrovascular diseases in Brazil: a nationwide analysis of longitudinal data. BMJ 2014;349: g4014.

DOI: 10.1056/NEJMp1501140

Copyright (C) 2015 Massachusetts Medical Society.

\section{A NICE Delivery - The Cross-Atlantic Divide over Treatment Intensity in Childbirth}

\author{
Neel Shah, M.D., M.P.P.
}

For generations, both British Cand American mothers have assumed that the safest way to give birth is to spend many hours, if not days, in a hospital bed under the supervision of an obstetrician. Now, new guidelines are challenging these deeply held beliefs.
After completing an evidencebased review, the United Kingdom's National Institute for Health and Care Excellence (NICE) concluded that healthy women with straightforward pregnancies are safer giving birth at home or in a midwife-led unit than in a hospi- tal under the supervision of an obstetrician. ${ }^{1}$ Across the pond, eyebrows went up. The New York Times editorial board (and others) wondered, "Are midwives safer than doctors?" be safer than hospitals? And what implications will the British 